Proc. of the 15th Int. Workshop on Slow Positron Beam Techniques and Applications, Prague, September 2-6, 2019

\title{
Early Stages of Precipitation in Mould-Cast, Cold-Rolled and Heat-Treated Aluminium Alloy AA7075 with Sc,Zr-Addition
}

\author{
V. Kodetová*, M. Vlach, J. ČížEK, M. Cieslar, L. Bajtošová, H. Kudrnová, \\ M. LEIBNER AND V. Š́mA \\ Charles University, Faculty of Mathematics and Physics, Ke Karlovu 3, 12116 Prague, Czech Republic
}

\begin{abstract}
Precipitation reactions of the commercial $\mathrm{Al}-\mathrm{Zn}-\mathrm{Mg}-\mathrm{Cu}(-\mathrm{Sc}-\mathrm{Zr})$ alloy in mould-cast, cold-rolled, and heattreated states were characterized by electron microscopy, X-ray diffraction, thermal analysis, microhardness testing, and positron annihilation spectroscopy. The distinct changes in microhardness curves as well as in a heat flow of the alloys studied are mainly caused by dissolution of clusters and precipitation of particles from the $\mathrm{Al}-\mathrm{Zn}-\mathrm{Mg}-\mathrm{Cu}$ system. An easier diffusion of $\mathrm{Zn}, \mathrm{Mg}$, and $\mathrm{Cu}$ atoms along dislocations is responsible for the precipitation of $\mathrm{Zn}, \mathrm{Mg}, \mathrm{Cu}$-containing particles at lower temperatures compared to the mould-cast alloys The mould-cast and coldrolled alloys contain solute clusters rich in $\mathrm{Mg}$ and $\mathrm{Zn}$. Clusters formed in the heat-treated alloys during natural ageing have similar composition but in addition to $\mathrm{Mg}$ and $\mathrm{Zn}$ contain also $\mathrm{Cu}$. The $\mathrm{Cu}$-concentration increases with increase of period of natural ageing. The mould-cast state after natural ageing contain in addition to solute agglomerates also vacancy clusters formed by agglomeration of thermal vacancies. Addition of Sc and $\mathrm{Zr}$ results in a higher hardness above $\approx 270^{\circ} \mathrm{C}$ due to a strengthening by $\mathrm{Al}_{3}(\mathrm{Sc}, \mathrm{Zr})$ particles with a good thermal stability. Sc and Zr have probably no influence on the evolution of solute clusters.
\end{abstract}

DOI: 10.12693/APhysPolA.137.250

PACS/topics: 81.30.Mh, 81.40.Cd, 84.37.+q, 68.37.Lp

\section{Introduction}

Commercial Al-Zn-Mg-Cu-based alloys (AA7xxx series) exhibit reasonable solid solution hardening [1]. Mechanical properties of these alloys depend on a chemical composition, mainly on $\mathrm{Zn}$ and $\mathrm{Mg}$ contents and on a heat treatment of the studied alloys [2-5]. Although different authors used various notations for phases formed in the early precipitation stage, multiple publications (e.g. Refs. $[2-8]$ ) are consistent with the following precipitation sequences: (a) supersaturated solid solution (SSS) $\rightarrow$ clusters/Guinier-Preston (GP) zones $\rightarrow \eta^{\prime}$-phase $\rightarrow$ $\eta$-phase, (b) SSS $\rightarrow$ clusters/GP zones $\rightarrow T^{\prime}$-phase $\rightarrow$ $T$-phase. The $\eta^{\prime}$-phase precipitates play a major role in the strengthening of the alloys [8]. But the formation of metastable precipitates depends on the alloy composition, artificial ageing temperature, ageing time, heat treatment etc. $[3-5]$.

An addition of Sc $(\approx 0.2 \mathrm{wt} \%)$ and $\mathrm{Zr}(\approx 0.1 \mathrm{wt} \%)$ to Al-based alloys is used to refine the cast grain structure, to increase recrystallization temperature, and to improve their mechanical properties $[9,10]$. Consequently, there is an interest in a further improvement of properties of $\mathrm{Al}-\mathrm{Zn}-\mathrm{Mg}-\mathrm{Cu}$-based alloys containing $\mathrm{Sc}$ and $\mathrm{Zr}$ and a study of their microstructure and mechanical properties [9]. Despite the fact that the AA7xxx series alloys belong to the most extensively used Al-based

* corresponding author; e-mail: veronika.kodetova@seznam.cz alloys $[4,5,9,10]$, relatively few studies have investigated phase transformations of the $\mathrm{Al}-\mathrm{Zn}-\mathrm{Mg}-\mathrm{Cu}$-based alloys with Sc,Zr-addition. A tailoring of the material with required properties is very difficult without a detailed knowledge of the precipitation processes and the role of $\mathrm{Sc}$ and $\mathrm{Zr}$ in the microstructure development.

\section{Experimental details}

The mould-cast (MC) Al-5.4wt\% $\mathrm{Zn}-3.1 \mathrm{wt} \% \mathrm{Mg}-$ $1.5 \mathrm{wt} \% \mathrm{Cu} \quad(7075)$ and $\mathrm{Al}-5.2 \mathrm{wt} \% \mathrm{Zn}-3.0 \mathrm{wt} \% \mathrm{Mg}-$ $1.4 \mathrm{wt} \% \mathrm{Cu}-0.2 \mathrm{wt} \% \mathrm{Sc}-0.1 \mathrm{wt} \% \mathrm{Zr} \quad(7075-\mathrm{ScZr}) \quad$ were studied. Both alloys were also cold-rolled (CR) using $21 \%$ thickness reduction. High temperature (HT) treatment of the $\mathrm{MC}$ alloys was performed at $475^{\circ} \mathrm{C} / 60 \mathrm{~min}$ in a furnace with an Ar protective atmosphere and was finished by a quenching.

The influence of isochronal annealing (in steps of $30 \mathrm{~K} / 30 \mathrm{~min}$ ) on mechanical properties was studied using Vickers microhardness (HV0.5) measured at $\approx 0{ }^{\circ} \mathrm{C}$. To avoid a possible natural ageing (NA), after quenching, the materials were kept in liquid nitrogen at $78 \mathrm{~K}$ until measurements or the next annealing step. The annealing procedure was performed exactly in the same way as described in Refs. $[10,11]$. The thermal behaviour of the alloys was studied using differential scanning calorimetry (DSC) performed using the heating rate of $20 \mathrm{~K} / \mathrm{min}$ in the Netzsch 200 F3 Maia apparatus. Positron annihilation spectroscopy (PAS) was employed for an investigation of lattice defects. PAS measurements were performed using a ${ }^{22} \mathrm{Na}$ positron source with activity of $1 \mathrm{MBq}$ sealed between $2 \mu \mathrm{m}$ thick mylar foils. Positron 
lifetime (LT) investigations were performed using a digital spectrometer [12] with a time resolution of 143 ps. Coincidence Doppler broadening (CDB) studies were carried out on a digital spectrometer [13] with an energy resolution of $0.9 \mathrm{keV}$ at the annihilation line. Detailed information about measurements is described in Ref. [14]. The microstructure evolution was characterized by transmission (TEM) and scanning (SEM) electron microscopy. TEM and SEM observations were carried out in JEOL JEM 2000FX, 2200FS and MIRA I Schottky FE-SEMH microscopes. The analysis of precipitated phases was complemented by energy-dispersive spectroscopy (EDS) performed by X-ray BRUKER microanalyser.

\section{Results and discussion}

SEM and EDS proved presence of a $\mathrm{Zn}, \mathrm{Mg}, \mathrm{Cu}$-containing eutectic phase at grain boundaries in the initial MC and CR state of both 7075 and 7075-Sc,Zr alloy. The initial HV0.5 values of 7075 and 7075-ScZr alloy (Fig. 1) are enhanced for CR samples due to work hardening by dislocations. Only small density of dislocations in grain interiors was observed by TEM in the MC alloys. After cold rolling the amount of dislocations rapidly increase - see Fig. 2. Although any particles (except for the eutectic phase mentioned above) were not directly

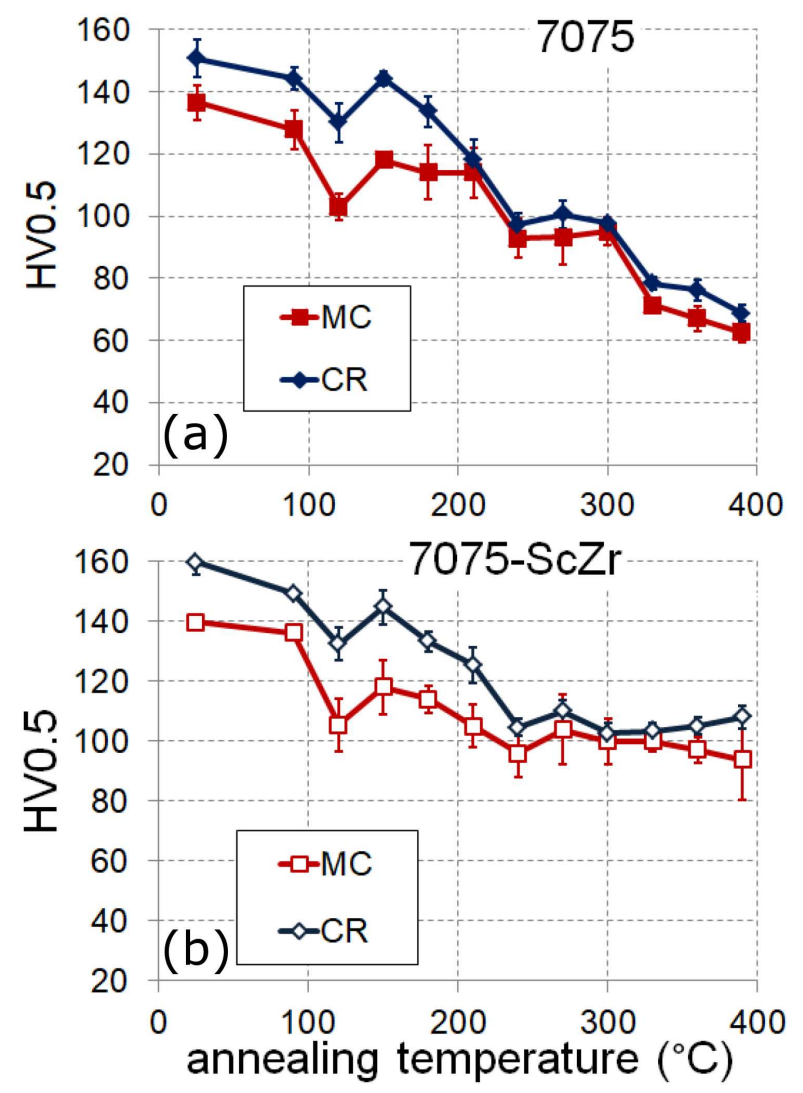

Fig. 1. Isochronal annealing HV curves of the (a) 7075 and (b) 7075-ScZr alloys.

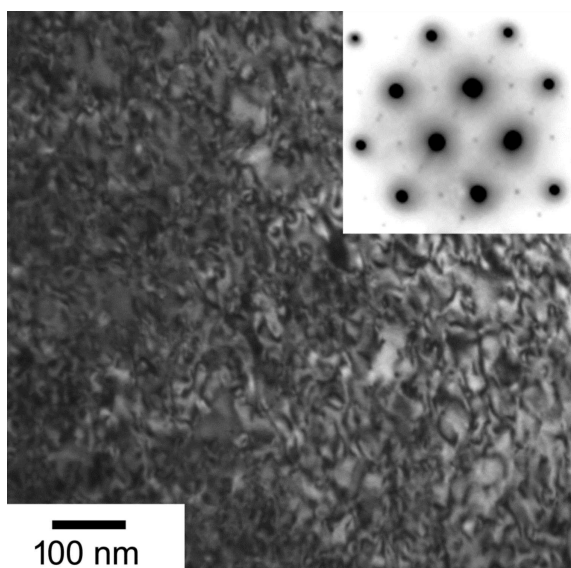

Fig. 2. TEM of the CR sample with $L 1_{2}$ structured particles (ED pattern).

observed by TEM, the existence of the $L 1_{2}$-structured particles was confirmed in the 7075-ScZr alloy by electron diffraction (ED), as well as some diffuse diffraction spots most probably from early precipitation stages (Fig. 2). They can be attributed to the presence of the secondary $\mathrm{Al}_{3}(\mathrm{Sc}, \mathrm{Zr})$ particles with $L 1_{2}$-structure and clusters/GP zones. Thus, higher initial HV0.5 values of $7075-\mathrm{Sc}, \mathrm{Zr}$ alloy compared to 7075 one are likely due to hardening effect of the Sc,Zr-addition.

Figure 3 shows DSC curves up to $390^{\circ} \mathrm{C}$. Three processes were detected: an endothermic effect (labelled A) followed by an exothermic (B) and a slight exothermic effect $(\mathrm{C})$. The maximum of the effect $\mathrm{B}$ is shifted to lower temperatures in the $\mathrm{CR}$ alloys.

Based on our previous study [8], it can be assumed that clusters/GP zones are being formed during cooling after casting and subsequent NA of the $7075(-\mathrm{ScZr})$ alloys. PAS measurements showed that positrons annihilated at traps in the MC state of the alloys are associated with small clusters characterized by a positron lifetime of $0.218-0.226 \mathrm{~ns}$. This value is in a good agreement with the results reported in Ref. [15] and corresponds to positron annihilations in clusters/GP zones. Considering the isochronal $\mathrm{HV}$ annealing curves with a local maximum at $\approx 150{ }^{\circ} \mathrm{C}$ (see Fig. 1 ) and the existence of the endothermic effect A (see Fig. 3) it can be concluded that clusters/GP zones present in the MC state were dissolved during annealing $475^{\circ} \mathrm{C} / 60 \mathrm{~min}$.

Figure 4 a shows TEM image of the $7075-\mathrm{ScZr}$ alloy in the MC state isochronally annealed up to $210^{\circ} \mathrm{C}$. Microstructure observations combined with ED and EDS proved presence of the metastable $\eta^{\prime}$-phase precipitates and in addition presence of the $T$-phase $\left(\mathrm{Al}_{2} \mathrm{Zn}_{3} \mathrm{Mg}_{3}\right)$ and $S$-phase $\left(\mathrm{Al}_{2} \mathrm{CuMg}\right)$ particles. In $\mathrm{Al}-\mathrm{Zn}-\mathrm{Mg}(-\mathrm{Cu})$-based alloys the metastable $\eta^{\prime}$-phase is a typical hardening phase $[2-5,8]$. On the other hand, precipitation of both $T$ - and $S$ - phases does not lead to any significant hardening $[2-6,8]$. According to the previous investigations (e.g. Refs. $[8,16,17]$ ) particles of the metastable $\eta^{\prime}$-phase were observed at comparable tem- 

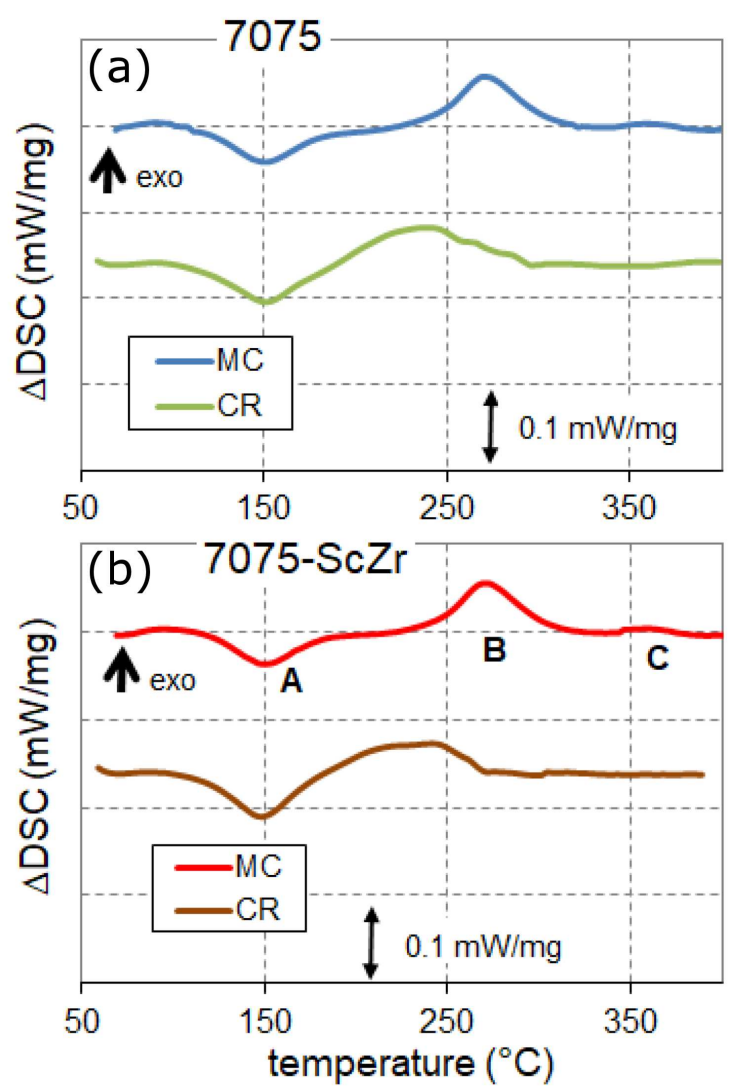

Fig. 3. DSC curves of the MC and CR alloys at heating rate of $20 \mathrm{~K} / \mathrm{min}$.

peratures both in AlZnMgScZr and AlZnMgCuScZr alloys. The hardening peak in the temperature range of $150-240^{\circ} \mathrm{C}$, as well as the exothermic B effect is associated with a formation of the $\eta^{\prime}$-phase. It should be mentioned that possible temperature ranges of the phase transformations are often shifted to higher temperatures with increase of heating rate. This is why the exothermic peak B is located at higher temperature than the peak hardness. Maxima of the DSC peaks are shifted to lower temperatures by cold rolling which is probably caused by an easier diffusion of $\mathrm{Mg}, \mathrm{Zn}$, and $\mathrm{Cu}$ atoms along dislocations.

Figure $4 \mathrm{~b}$ shows TEM image of the $7075-\mathrm{ScZr}$ alloy in the CR state isochronally annealed up to $360^{\circ} \mathrm{C}$, where dispersion of the particles can be seen. These particles were identified using ED and EDS as either $\eta$ - and/or $T$-phase. It can be concluded that the weak exothermic process $\mathrm{C}$ is probably related to the formation of these particles. Additional precipitation of the secondary $\mathrm{Al}_{3}(\mathrm{Sc}, \mathrm{Zr})$ particles was observed in the $7075-\mathrm{ScZr}$ alloy - this phase was detected by ED in the 7075-ScZr samples annealed up to $360^{\circ} \mathrm{C}$ (see Fig. 4b). The precipitation of $\mathrm{Al}_{3}(\mathrm{Sc}, \mathrm{Zr})$ particles is the reason for a more pronounced hardening of the alloy with Sc,Zr-addition, see Fig. 1.

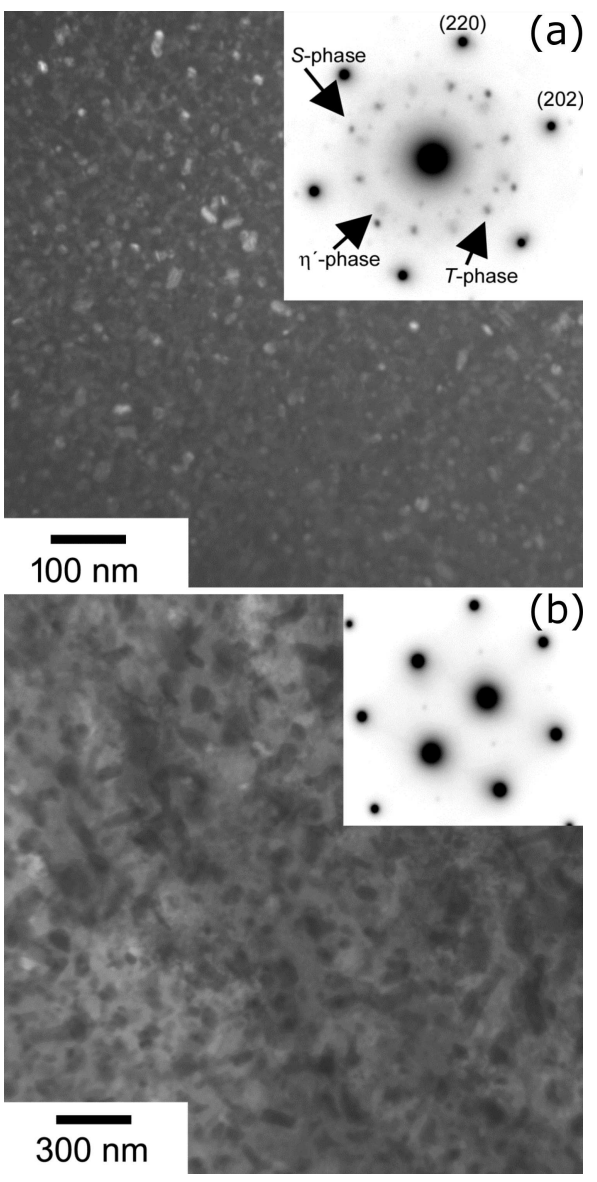

Fig. 4. TEM and ED of the (a) MC alloy annealed up to $210^{\circ} \mathrm{C}$, (b) $\mathrm{CR}$ alloy annealed up to $360^{\circ} \mathrm{C}$.

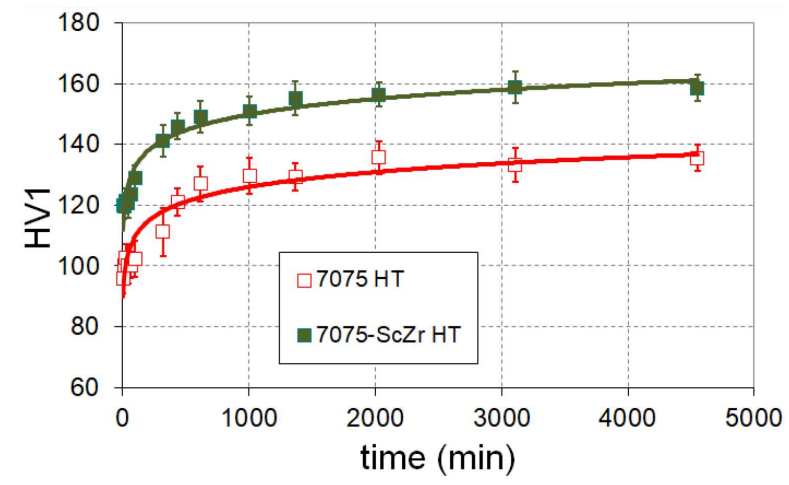

Fig. 5. HV evolution of the HT alloys during NA.

Figure 5 shows the variations of the microhardness during NA of the HT alloys. HV increases immediately after quenching to room temperature. Higher $\mathrm{HV}$ values of $7075-\mathrm{ScZr}$ alloy reflect strengthening due to Sc,Zr-addition. From comparison of the HV0.5 values of MC and HT alloys (cf. Figs. 1 and 5) it can be concluded that clusters/GP zones are dissolved during the heat treatment at $475^{\circ} \mathrm{C} / 60 \mathrm{~min}$. Owing to the strengthening effect of clusters/GP zones, HV0.5 


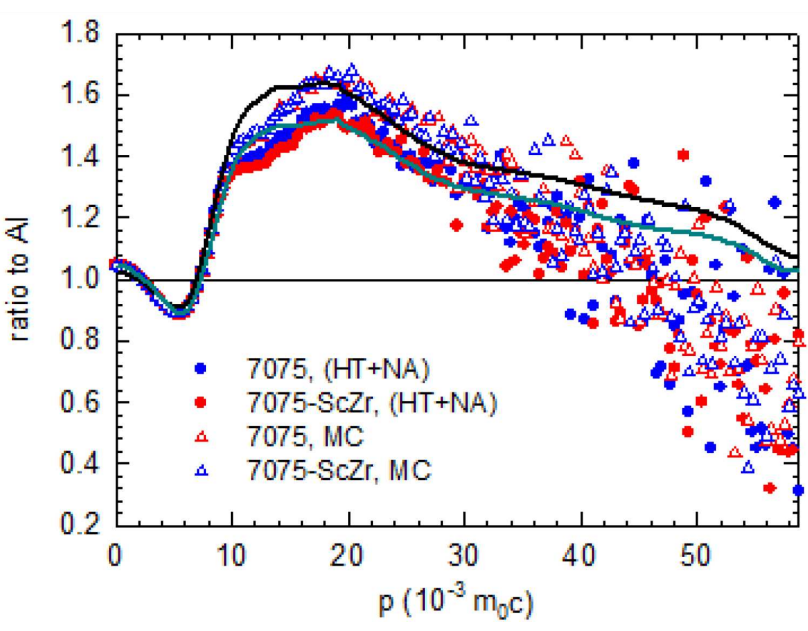

Fig. 6. CDB ratio curves (related to well annealed $\mathrm{Al}$ ) for 7075 and $7075-\mathrm{ScZr}$ alloys in the MC state and HT state after NA (HT+NA). Solid lines represent superposition of contributions of positrons annihilated by pure elements $\mathrm{Al}, \mathrm{Zn}, \mathrm{Mg}$ and $\mathrm{Cu}$.

increases continuously during NA due to the formation of solute clusters. This is in agreement with other studies of $\mathrm{Al}-\mathrm{Zn}-\mathrm{Mg}(-\mathrm{Cu})$-based alloys (e.g. Ref. [8]).

LT spectra of the HT alloys after NA consist of two components: (i) a shorter component with a lifetime $\tau_{1} \approx 221 \mathrm{ps}$ and intensity $I_{1} \approx 91 \%$ represents a contribution of positrons trapped at $\mathrm{Zn}, \mathrm{Mg}(\mathrm{Cu})$-containing solute clusters; (ii) a longer component with lifetime $\tau_{2} \approx 440 \mathrm{ps}$ and intensity $I_{2} \approx 9 \%$ comes from positrons trapped at vacancy clusters. Figure 6 shows the CDB ratio curves (related to pure $\mathrm{Al}$ ) of 7075 and $7075-\mathrm{ScZr}$ alloys in the MC state and in the HT state after NA. One can see in the figure that the ratio curves for 7075 and 7075-ScZr alloys are almost the same. It indicates that addition of Sc and $\mathrm{Zr}$ has negligible influence on positron trapping. Solutes of Sc and $\mathrm{Zr}$ are, thereby, not incorporated into solute clusters formed during NA or cooling after casting. Note that $\mathrm{Al}_{3}(\mathrm{Sc}, \mathrm{Zr})$ particles do not represent positron trapping sites [14]. There is, however, a difference between ratio curves for alloys in the MC state and in the HT state after NA. The CDB ratio curves of 7075 and 7075 -ScZr alloys can be well described assuming that positrons are annihilated in the vicinity of $\mathrm{Zn}(28 \%)$ and $\mathrm{Mg}(25 \%)$ atoms for the MC alloys and $\mathrm{Zn}$ (27\%), $\mathrm{Mg}(18 \%)$, and $\mathrm{Cu}(4 \%)$ atoms for the HT alloys after NA. The fractions of positrons annihilated in the vicinity of $\mathrm{Mg}, \mathrm{Zn}$, and $\mathrm{Cu}$ atoms are clearly substantially higher than the concentrations of these elements in the alloy. This indicates that the local chemical environment of positron traps is enriched in $\mathrm{Mg}, \mathrm{Zn}$, and $\mathrm{Cu}$, i.e., coherent clusters were formed predominantly by these elements.

Figure 7 shows the development of the $S$ and $W$ parameter during NA of the 7075-ScZr alloy in the HT state and re-annealed state. From inspection of Fig. 7

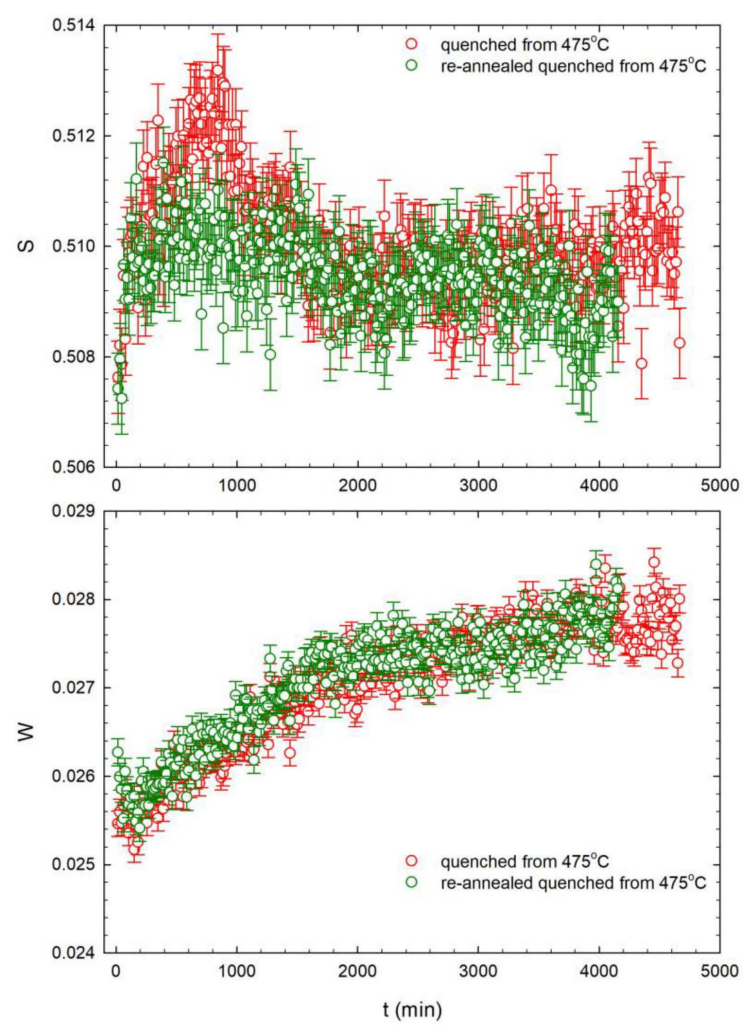

Fig. 7. The development of $S$ and $W$ parameter of 7075-ScZr alloy during NA.

one can conclude that at the beginning of NA parameter $S$ increases first and it is accompanied by a decrease of $W$. After reaching a local maximum at NA period of $\approx 720$ min parameter $S$ decreases again and it is accompanied by gradual increase of $W$. Hence, in early stages of NA solute clusters with imperfect structure containing vacancies are formed. This is reflected by an increase of $S$ and a decrease of W. Later the development of solute clusters takes place, their structure is improved and vacancies are gradually removed. This leads to subsequent drop of $S$ after reaching a local maximum at $\approx 720$ min. With increasing NA period the composition of solute clusters develops. Most probably the clusters become enriched in $\mathrm{Cu}$ which is reflected by a gradual increase of W. After NA the samples were re-annealed at $475^{\circ} \mathrm{C} / 60 \mathrm{~min}$ and NA was repeated. One can see that the development of $S$ and $W$ parameters after reannealing is similar to that in the first NA cycle.

The LT spectra of samples after NA consist of two components: (i) a contribution of positrons trapped at solute clusters with lifetime of $\tau_{1} \approx 222 \mathrm{ps}$ and intensity $I_{1} \approx 96 \%$, and (ii) a component with lifetime $\tau_{2} \approx 480 \mathrm{ps}$ and intensity $I_{2} \approx 5 \%$ representing a contribution of positrons trapped at vacancy clusters. Hence, comparing with samples in the MC state LT spectra exhibit similar components but intensity of the component corresponding to vacancy clusters is slightly lower. This indicates that solute clusters formed during NA are similar to those in the mould-cast samples. 


\section{Conclusions}

Results of characterization of mould-cast, cold-rolled, and heat-treated alloys can be summarized in the following points:

- The initial microhardness values of the alloys reflect the cold rolling. Easier diffusion of $\mathrm{Zn}$, $\mathrm{Mg}$, and $\mathrm{Cu}$ atoms along dislocations in the coldrolled alloys is responsible for the precipitation of $\mathrm{Zn}, \mathrm{Mg}, \mathrm{Cu}$-containing particles at the lower temperatures compared to the mould-cast alloys.

- The distinct changes in microhardness curves, as well as in the heat flow of the alloys are mainly caused by the dissolution of clusters/GP zones and precipitation of particles from the $\mathrm{Al}-\mathrm{Zn}-\mathrm{Mg}-\mathrm{Cu}$ system. Strengthening effect due to the formation of GP zones and/or growing of clusters is observed during natural ageing.

- Addition of Sc,Zr results in a higher hardness above $\approx 270^{\circ} \mathrm{C}$ due to the strengthening by $\mathrm{Al}_{3}(\mathrm{Sc}, \mathrm{Zr})$ particles.

- CDB investigations revealed that mould-cast alloys contain solute clusters rich in $\mathrm{Mg}$ and $\mathrm{Zn}$. Solute clusters formed in the heat-treated alloys during natural ageing have similar composition but in addition to $\mathrm{Mg}$ and $\mathrm{Zn}$ contain also $\mathrm{Cu}$. The concentration of $\mathrm{Cu}$ in solute clusters increases with increase of period of natural ageing. Addition of Sc and $\mathrm{Zr}$ has no influence on the development of solute clusters. LT investigations revealed that alloys in the mould-cast state and after natural ageing contain in addition to solute agglomerates also vacancy clusters formed by agglomeration of thermal vacancies.

\section{Acknowledgments}

This work was supported by The Czech Science Foundation (GACR, project no. 17-17139S). Authors are also grateful to Bohumil Smola for his experimental help.

\section{References}

[1] T. Dursun, C. Soutis, Mater. Des. 56, 862 (2014).

[2] K.R. Prasanta, M.M. Ghosh, K.S. Ghosh, Mater. Character. 104, 49 (2015)

[3] N. Afify, A. Gaber, G. Abbady, Mater. Sci. Appl. 2, 427 (2011).

[4] K.S. Ghosh, N. Gao, M.J. Starink, Mater. Sci. Eng. A 552, 164 (2012).

[5] K.S. Ghosh, N. Gao, Trans. Non-Met. Soc. China 21, 1199 (2011).

[6] C. Antonione, F. Marino, G. Riontino, S. Abis, E. Russo, Mater. Chem. Phys. 20, 13 (1988).

[7] S. Abis, G. Riontino, Mater. Lett. 5, 442 (1987).

[8] M. Vlach, V. Kodetová, B. Smola, J. Č́žžek, T. Kekule, M. Cieslar, H. Kudrnová, L. Bajtošová, M. Leibner, I. Procházka, Kovové Mater.-Metall. Mater. 56, 367 (2018)

[9] L.S. Toropova, D.G. Eskin, M.L. Kharakterova, T.V. Dobatkina, in: Advanced Aluminium Alloys Containing Scandium-Structure and Properties, Gordon and Breach Science Publisher, The Netherlands, 1998.

[10] M. Vlach, I. Stulíková, B. Smola, T. Kekule, H. Kudrnová, V. Kodetová, V. Očenášek, J. Málek, V. Neubert, Kovové Mater.-Metallic Mater. 53, 295 (2015).

[11] J. Čížek, I. Procházka, B. Smola, I. Stulíková, M. Vlach, V. Očenášek, O.B. Kulyasova, R.K. Islamgaliev, Int. J. Mater. Res. 100, 6 (2009).

[12] F. Bečvář, J. Čížek, I. Procházka, J. Janotová, Nucl. Inst. Methods Phys. Res. A 539, 372 (2005).

[13] J. Čížek, M. Vlček, I. Procházka, Nucl. Instrum. Methods Phys. Res. A 623, 982 (2010).

[14] M. Vlach, J. Č́žek, O. Melikhova, I. Stulíková, B. Smola, T. Kekule, H. Kudrnová, R. Gemma, V. Neubert, Metall. Mater. Trans. A 46, 1556 (2015).

[15] G. Dlubek, R. Krause, O. Brommer, J. Mater. Sci. 21, 853 (1986).

[16] P. Lang, T. Wojcik, E. Povoden-Karadeniz, A. Falahati, E. Kozeschnik, J. Alloys Comp. 609 , 129 (2014).

[17] J. Tang, H. Chen, X. Zhang, S. Liu, W. Liu, H. Ouyang, H. Li, Trans. Nonferr. Met. Soc. China 22, 1255 (2012). 